\title{
SIMULASI SENSOR TETESAN CAIRAN, PADA INFUS KONVENSIONAL
}

\author{
Wadianto $^{1}$, Zhafira Fihayah ${ }^{2}$ \\ 1.2Jurusan Teknik Elektromedik Politeknik Kemenkes Jakarta II \\ Email:wadianto_anto@yahoo.com
}

\begin{abstract}
Sensor Simulation of Liquid Droplets in Conventional Infus. Infusion pump is a device introducing a fluid into the patient's body in a certain amount through the veins of patients continuously in a certain period. In conventional infusion tool, the monitoring of droplets number is done manually which Accuracy is questionable. Preparation of Monitoring Total Fluid Droplets On Conventional Infusion module was considered to determine the accuracy of the number of fluid droplets. This study was to get a counting system at Infusion Conventional liquid droplets. The study took place in two stages of implementation, the first stage was preparation of tools and second stage was a laboratory testing tools at Electronics Laboratory, Medical Electronic Engineering Department. Pump Infussion tool was equipped with a optocoupler sensor circuit as a detector of drip number that has been entered into the patient's body. This tool was also equipped with indicators that tell if the infusion liquid has run out or the droplet was not flowing. Module that have been designed was able to work well when there was an error, such as the bottle was empty or the drip was not drop into the drip chamber, and the counting accuracy of the number of droplets were $96.2 \%$ per minute.
\end{abstract}

Keywords: Sensor, Infus, Liquid droplets

\begin{abstract}
Abstrak: Simulasi Sensor Tetesan Cairan, pada Infus Konvensional. Infus Pump adalah alat memasukkan suatu cairan kedalam tubuh pasien dalam jumlah tertentu melalui pembuluh vena pasien yang dilakukan secara terus menerus dalam jangka waktu tertentu. Pada alat infus konvensional untuk memonitor jumlah tetesan dilakukan secara manual yang keakurasiannya masih diragukan. Pembuatan modul Monitoring Jumlah Tetesan Cairan Pada Infus Konvensional dianggap dapat menentukan keakurasian jumlah tetesan cairan. Tujuan dari penelitian ini adalah untuk mendapatkan sistem penghitungan tetesan cairan pada Infus Konvensional. Penelitian berlangsung dalam dua tahap pelaksanaan, yaitu tahap pertama pembuatan alat dan tahap kedua pengujian alat di laboratorium Elektronika Jurusan Teknik Elektromedik. Alat Infussion Pump ini dilengkapi dengan rangkaian Sensor Optocoupler sebagai pendeteksi jumlah tetesan infus yang telah masuk ke dalam tubuh pasien. Alat ini dilengkapi pula dengan indikator yang memberitahukan apabila cairan infus sudah habis ataupun ketika tetesan tersebut tidak mengalir. Modul yang dirancang ini hasilnya bekerja aktif saat adanya kesalahan yaitu botol kosong atau tetesan tidak menetes ke drip chamber dan keakurasian menghitung jumlah tetesan cairan per menit sebesar $96,2 \%$.
\end{abstract}

Kata kunci: Sensor, Infus, Tetesan cairan

Alat Kedokteran sebagai fungsi diagnostik dan terapi sangat berkaitan dengan dua aspek, yaitu aspek keselamatan dan aspek keamanan bagi pasien. Infusion pump adalah suatu peralatan medis yang difungsikan untuk memasukkan cairan ke dalam tubuh manusia baik berupa vitamin dalam bentuk cair atau zat lain yang ingin dimasukkan kedalam tubuh melalui media cairan. Alat ini memiliki fungsi yang cukup penting dalam pelayanan medis khususnya dalam perawatan pasien yang kritis, karena cairan yang dimasukkan dengan menggunakan alat ini langsung melalui pembuluh darah (vena), sehingga cairan yang dimasukkan bisa langsung diolah oleh tubuh karena cairan itu langsung diangkut oleh darah menuju bagian tubuh yang memerlukan (Dian Wiris, 2012).

Pada saat sekarang ini hampir seluruh rumah sakit telah memiliki sistem peralatan kesehatan yang canggih dan modern. Hal ini membuat pekerja medis menjadi lebih praktis dan cepat. Sehingga pelayanan yang diberikan oleh rumah sakit tersebut lebih baik. Kecanggihan pada peralatan kesehatan juga membuat semakin mahalnya harga alat tersebut. Kecanggihan dalam bidang kesehatan tersebut juga di alami oleh alatalat life support, seperti nebulizer, baby incubator, infant warmer, suction pump, ventilator, terutama infuse pump. Alat infus pump merupakan salah satu penunjang medis yang 
biasa digunakan didalam ruang gawat darurat, ruang rawat inap, ruang rawat intensif dan ruang khusus lainnya. Alat infus adalah alat injeksi cairan kimia tertentu yang diberikan kepada pasien dalam rangka pengobatan berupa cairan nutrisi, tranfusi darah. Di ruang rawat inap ada beberapa pasien yang dalam pemberian infus harus dikontrol oleh perawat. Cairan yang masuk dalam tubuh pasien selalu berbeda-beda sesuai kebutuhannya, sehingga perawat harus selalu mengontrol pasien. Untuk itu dicoba untuk membuat suatu sistem yang mempermudah perawat untuk mengontrol pada pemberian infus untuk pasien.

Semua sistem yang akan dibuat menggunakan sistem kontrol yang memanfaatkan mikrokontroller sebagai pengembangan dari sistem kontrol manual maupun digital.

Maka dapat disimpulkan tujuan penelitian ini adalah :

1. Merancang dan membuat modul monitoring jumlah tetesan cairan pada infus konvensional.

2. Melakukan pendataan dan analisis modul monitoring jumlah tetesan cairan pada infus konvensional.

Batasan masalah yang digunakan dalam pelaksanaan penelitian ini adalah membatasi parameter yang akan dibahas dalam tulisan ini yaitu memonitoring jumlah tetesan cairan, menampilkan volume cairan yang telah digunakan pada drip chamber dan mendeteksi cairan ketika telah habis.

Tujuan dari pembuatan modul simulasi ini adalah untuk:

1. Merancang apakah modul yang dibuat dapat bekerja dengan baik serta untuk mengetahui tingkat keakurasiannya.

2. Untuk mengetahui apakah modul monitoring jumlah tetesan cairan pada infus konvensional mampu mendeteksi bila terjadi kesalahan pada inputnya.

\section{GAMBARAN UMUM INFUS PUMP}

Infus pump merupakan salah satu alat kesehatan yang berfungsi untuk memasukan cairan infus ke dalam tubuh pasien secara otomatis. Infus adalahmemasukkan suatu cairan kedalam tubuh pasien dalam jumlah tertentu melalui intravena (pembuluh darah) penderita yang dilakukan secara terus menerus dalam jangka waktu tertentu. Tujuan dari pemberian cairan infus adalah untuk menggantikan cairan yang ada dalam tubuh pasien. Biasanya infus di berikan kepada pasien yang mengalami dehidrasi serta pada pasien yang akan melakukan operasi dan setelah melakukan operasi (Galih ND 2014). Pada gambar 1 terlihat alat infus pump secara fisik. Melalui gambar tersebut dapat diketahui bahwa alat tersebut terdapat tombol start, stop, sensor keypad untuk pengaturan jumlah cairan yang akan diberikan. Selain menggunakan supply dari PLN, alat ini juga menggunakan battery sebagai cadangan apabila terjadi pemutusan arus dari PLN sehingga alat dapat terus bekerja memberikan cairan infus ke pasien.

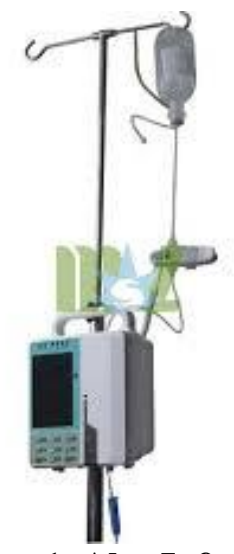

Gambar 1. Alat Infus Pump

\section{DRIP CHAMBER}

Drip chamber adalah wadah atau tempat yang digunakan untuk menampung cairan infus sebelum masuk ke dalam tubuh pasien. Pada drip chamber inilah sensor tetesan dan sensor botol kosong dipasang. Pada sensor tetesan akan mendeteksi setiap cairan yang masuk dari botol infus ke drip chamber, dan pada sensor botol kosong akan menangkap apabila volume cairan pada drip chamber berkurang karena tidak ada cairan infus lagi yang masuk ke dalam drip chamber (Wikipedia, Nov 2016).

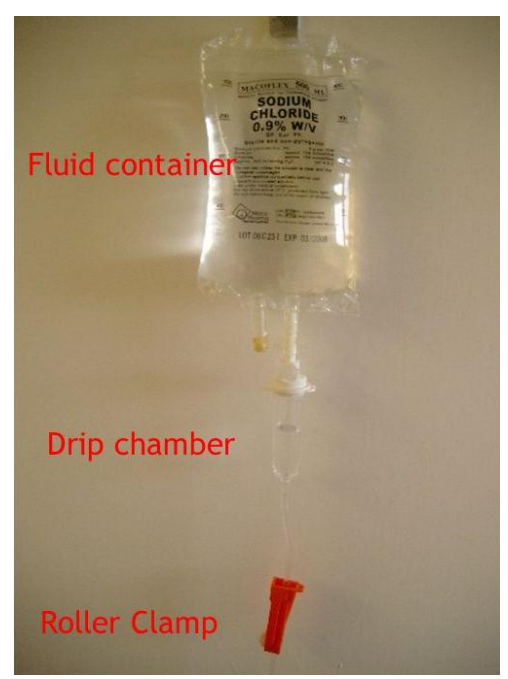

Gambar 2. Drip Chamber 


\section{METODE PERANCANGAN MODUL}

Perancangan sistem yang dijadikan penelitian memiliki beberapa langkah di dalam penyelesaiannya. Desain dari miniatur yang dirancang diperlukan agar sistem yang akan diimplementasikan tidak keluar dari tujuan awal. Sehingga pada proses perancangan modul ini dibagi menjadi 2 tahap yaitu :

1. Studi literatur yaitu: (1) mengumpulkan berbagai informasi dari buku-buku, skripsi, tesis, maupun jurnal, yang berkaitan dengan sistim sensor alir cairan. (2) Mempelajari sistim pengolahan input data dari sensor menjadi output yang bisa dibaca oleh perawat pengguna infus pump.

2. Perancangan software dan hardware sebagai berikut; (1) perancangan software pada mikrokontroler Arduino Pro Mini Atmega 328 menggunakan bahasa program, (2) perancangan hardware berupa perancangan rangkaian elektronik.

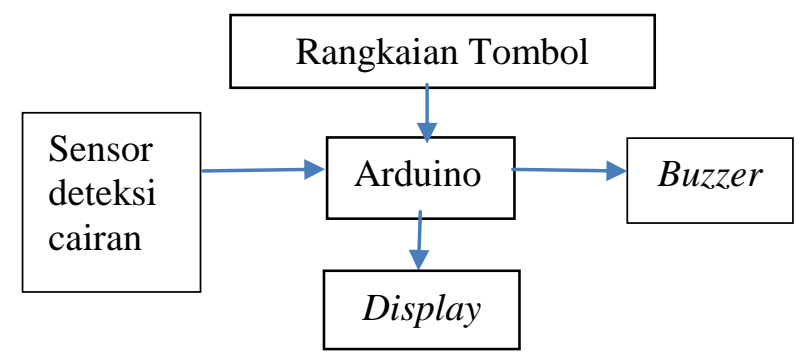

\section{Gambar 3. Blok Diagram}

Secara keseluruhan alat simulasi ini bekerja dengan menggunakan baterai (Tegangan 4.8 VDC) untuk handphone yang dapat di charge setiap saat diperlukan.

Perancangan modul dilaksanakan mulai bulan April sampai bulan Juni 2016, di ruang Praktikum Elektronika Jurusan Teknik Elektromedik Poltekkes Jakarta II.

\section{Sensor pendeteksi tetesan}

Berfungsi untuk menghitung jumlah tetesan yang jatuh pada drip chamber serta menghitung volume cairan yang telah dikeluarkan dari tabung infus permenitnya.

\section{Blok mikrokontroler}

Blok mikrokontroler merupakan pusat pengolahan data yang akan ditampilkan pada display, dengan menggunakan Arduino Pro Mini Atmega 328.

\section{Rangkaian tombol}

Blok ini berupa tombol "start" "stop" atau "reset" yang berfungsi untuk memulai perhitungan jumlah tetesan, untuk menghentikan perhitungan tetesan dan untuk mengulang penghitungan tetesan.

\section{Buzzer}

Sebagai indikator bunyi apabila tidak adanya tetesan.

\section{Display}

Blok ini merupakan tempat untuk menampilkan data yang telah diolah dari mikrokontroler, sehingga dapat dibaca oleh perawat sebagai tindakan yang akan diambilnya.

\section{SPESIFIKASI}

Spesifikasi sistem yang direncanakan dan direalisasikan dalam pembuatan modul ini dibagi menjadi spesifikasi fungsional dan spesifikasi teknis, sebagai berikut:

1. Spesifikasi Fungsional

Rangkaian ini di rancang untuk dapat memonitor jumlah tetsan dan mendeteksi cairan ketika tetesan tidak mengalir dalam hitungan permenit.

2. Spesifikasi Teknis

Spesifikasi alat yang direncanakan dalam pembuatan modul ini adalah sebagai berikut :

a. Menggunakan mikrokontroler berbasis arduino mikro

b. Menggunakan baterai 4,8 VDC sebagai power supply

c. Lcd 16 x 2 untuk tampilan display

d. Menampilkan hasil dari jumlah tetesan dan mendeteksi cairan ketika tetesan tidak mengalir dalam hitungan detik

\section{PERSIAPAN PENGUJIAN}

Modul yang telah selesai dibuat dilakukan pengujian berupa pengukuran output dengan parameter jumlah tetesan/menit dalam satuan waktu. Pengujian ini dilakukan di Ruang Praktikum Elektronika. Persiapan peralatan dan bahan guna proses pendataan sebagai berikut:

\section{a. Persiapan alat}

1. Tool set

2. Tiang infus

3. Drip chamber

4. Botol infus

5. Selang infus

6. Alat monitoring tetesan infus

\section{b. Persiapan bahan}

Komponen atau bahan yang digunakan dalam pembuatan alat 'simulasi monitoring 
jumlah tetesan pada infus konvensional' adalah sebagai berikut :

Rangkaian Mainboard untuk Mikrokontroler dan Display :

Tabel 1. Komponen Rangkaian

\begin{tabular}{llr}
\hline Komponen & Nilai / Jenis & Jumlah \\
\hline Arduino & Pro mini & 1 Buah \\
LCD & $16 \times 2$ & 1 Buah \\
Resistor & $10 \mathrm{k} \Omega$ & 3 Buah \\
& $470 \Omega$ & 2 Buah \\
& $15 \mathrm{~K} \Omega$ & 2 Buah \\
Push button & Start, Reset, & 3 Buah \\
& Stop & \\
Transistor & NPN & 1 Buah \\
Saklar & On/off & 1 Buah \\
IC Analog & LM 741 & 2 Buah \\
LED & Merah & 1 Buah \\
Buzzer & & 1 Buah \\
Konektor & Kapasitas 9 & 1 Buah \\
Baterai & Volt & \\
& Kapasitas & 1 Buah \\
& $4.8 \mathrm{Volt}$ & \\
Resistor & Multitun10K & 2 Buah \\
potensio & & \\
Dioda & $1 \mathrm{~N} 4007$ & 1 Buah \\
Kapasitor & $100 \mathrm{nF}$ & 2 Buah \\
Optocoupler & & 1 Buah \\
\hline
\end{tabular}

Setelah semua komponen dirangkai menjadi modul maka dilakukan pendataan pada rangkaian untuk di ukur. Pengukuran dilakukan pada waktu selama 1 menit, 5 kali pengukuran. Dalam pengukuran ini penulis menggunakan drip chamber berjenis makro untuk ukuran orang dewasa. Satu cc pada Drip chamber berukuran makro merupakan 20 tetesan per menit.

Untuk analisa hasil pengukuran, terlebih dahulu menggunakan rumus (Ninie Purnamasari 2011), sebagai berikut :

1. Rumus menghitung tetesan infus

Ukuran macro 20 tetesan per menit

$\frac{\text { tetesan }}{\text { menit }}=\frac{\text { jumlah cairan } \times 20}{\text { lama infus } \times 60}$

2. Rumus menghitung lama infus

$$
\frac{\text { jumlah cairan } \times 20}{\text { tetesan per menit } \times 60}
$$

Pengukuran ini menggunakan 20 tetesan per menit yang di dapat dari ketentuan di atas dan kemudian dibandingkan dengan hasil dari keluaran sensor di tampilan display.

Dalam pengukuran dan pengujian alat ini berisi tentang hasil yang telah didapatkan penulis selama melakukan pencarian data yang dibutuhkan. Berikut tabel hasil pengukuran dan pengujian alat:

Tabel 2. Hasil Pengukuran

\begin{tabular}{|c|c|c|c|c|}
\hline No. & $\begin{array}{l}\text { Jumlah } \\
\text { Tetesan } \\
\text { Cairan } \\
\text { (Dewasa) }\end{array}$ & $\begin{array}{c}\text { Jumlah } \\
\text { Tetesan } \\
\text { Cairan } \\
\text { pada } \\
\text { Tampilan } \\
\text { Alat } \\
\end{array}$ & $\begin{array}{c}\text { Waktu } \\
\text { yg } \\
\text { terukur }\end{array}$ & $\begin{array}{c}\text { Ke- } \\
\text { akurasi- } \\
\text { an }\end{array}$ \\
\hline 1 & $\begin{array}{l}20 \\
\text { tetesan/ } \\
\text { menit }\end{array}$ & $\begin{array}{l}25 \\
\text { tetesan/ } \\
\text { menit }\end{array}$ & 00:01:04 & $97 \%$ \\
\hline 2 & $\begin{array}{l}20 \\
\text { tetesan/ } \\
\text { menit }\end{array}$ & $\begin{array}{l}20 \\
\text { tetesan/ } \\
\text { menit }\end{array}$ & 00:01:04 & $96 \%$ \\
\hline 3 & $\begin{array}{l}20 \\
\text { tetesan/ } \\
\text { menit }\end{array}$ & $\begin{array}{l}20 \\
\text { tetesan/ } \\
\text { menit }\end{array}$ & $00: 01: 04$ & $96 \%$ \\
\hline 4 & $\begin{array}{l}20 \\
\text { tetesan/ } \\
\text { menit }\end{array}$ & $\begin{array}{l}20 \\
\text { tetesan/ } \\
\text { menit }\end{array}$ & 00:01:05 & $96 \%$ \\
\hline 5 & $\begin{array}{l}20 \\
\text { tetesan/ } \\
\text { menit }\end{array}$ & $\begin{array}{l}20 \\
\text { tetesan/ } \\
\text { menit }\end{array}$ & 00:01:05 & $96 \%$ \\
\hline $\begin{array}{l}\text { Rata- } \\
\text { rata }\end{array}$ & $\begin{array}{l}20 \\
\text { tetesan/ } \\
\text { menit }\end{array}$ & $\begin{array}{l}21 \\
\text { tetesan/ } \\
\text { menit }\end{array}$ & - & $96,2 \%$ \\
\hline
\end{tabular}

\section{PENGUJIAN ALAT}

Dalam pengukuran dan pengujian alat ini berisi tentang hasil yang telah didapatkan penulis selama melakukan pencarian data yang dibutuhkan. Berikut tabel hasil pengukuran dan pengujian alat: 


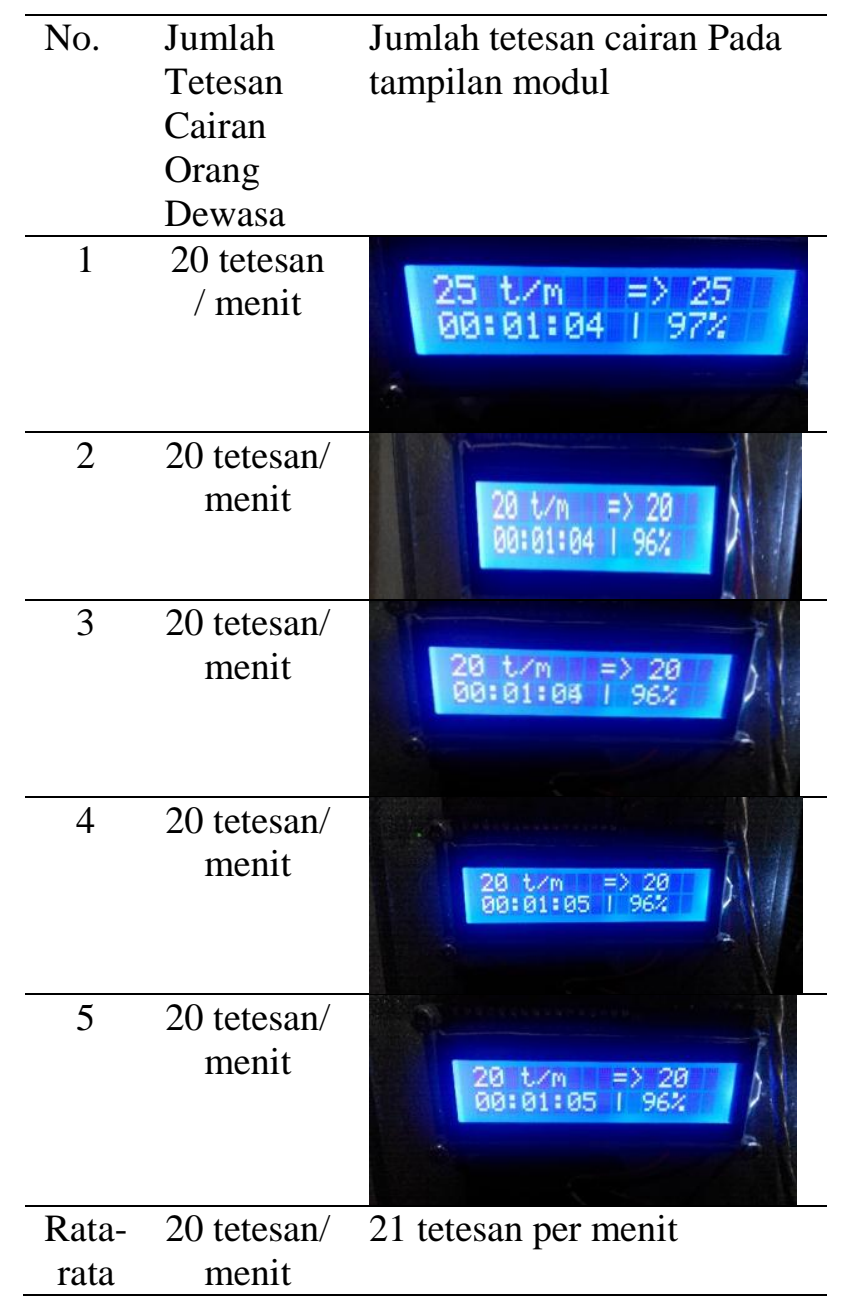

\section{PEMBAHASAN HASIL PENGUJIAN}

Secara keseluruhan pengujian modul sensor tetesan cairan pada infus konvensional dengan menggunakan sensor optocoupler berbasis mikrokontroler Arduino Pro Mini ini telah berhasil. Sumber daya rangkaian menggunakan baterai yang memberikan tegangan 4,8 volt yang masuk ke seluruh rangkaian untuk mengaktifkan semua sistem lalu memproses data melalui arduino yang kemudian ditampilkan pada layar LCD. Ketika tombol start di tekan maka alat mulai beroperasi. Lalu sensor optocoupler akan membaca jumlah tetesan dan mengontrol ada atau tidaknya cairan tetesan yang akan membuat buzzer berbunyi apabila tetesan tidak menetes yang kemudian diproses oleh arduino. Selanjutnya arduino akan melanjutkan pemrosesan data untuk kemudian ditampilkan di display.

Pembahasan selanjutnya adalah dari masing-masing rangkaian sebagai berikut:

\section{Rangkaian Display}

Rangkaian tersebut berfungsi untuk menampilkan data berupa angka atau huruf yang terlebih dahulu diolah di rangkaian mikrokontroler. Rangkaian display ini terdiri dari LCD 16x2 karakter. LCD ini dipergunakan untuk menampilkan jumlah tetesan yang telah dibaca oleh sensor (Jazi Eko Istiyanto, 2014) :

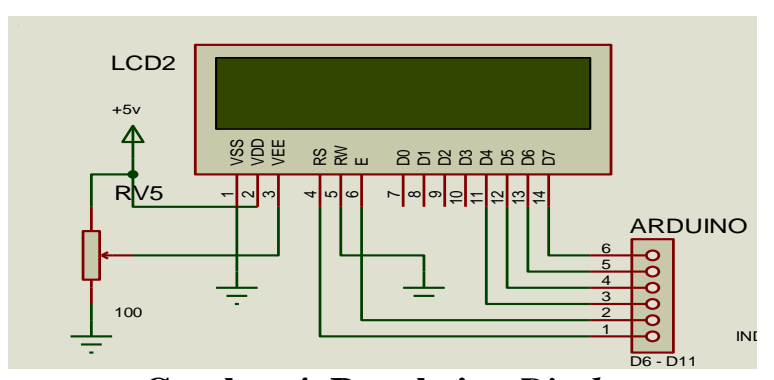

Gambar 4. Rangkaian Display

\section{Rangkaian Buzzer}

Rangkaian ini berfungsi memberikan indikator berupa bunyi/suara. Rangkaian ini terhubung dengan kaki 5 pada port D5 mikrokontroler arduino (Albert Paul, Malvino. 2003)

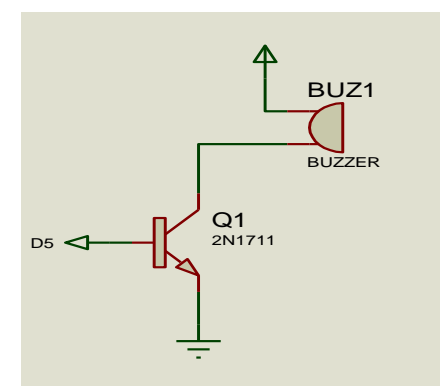

\section{Gambar 5. Rangkaian Buzzer}

\section{Rangkaian Arduino}

Alat yang dibuat ini berbasis mikrokontroller Arduino Atmega 328 disertai dengan tampilan LCD. Mikrokontroller ini terhubung dengan beberapa rangkaian pendukung lainnya, yaitu rangkaian buzzer, tombol, input sensor, dan display. Pada mikrokontroller tipe Arduino Atmega 328 rangkaian sistem minimum yang dibutuhkan lebih sedikit dari mikrokontroller tipe lain karena mikrokontroller jenis ini memiliki internal oscilator sehingga tidak membutuhkan tambahan dari luar, karenanya yang dibutuhkan hanyalah rangkaian reset yang terdapat pada port RST yang berfungsi untuk memberikan kondisi mikrokontroller menjadi kondisi awal secara manual jika tombol reset ditekan (Abdul Kadir, 2013). 


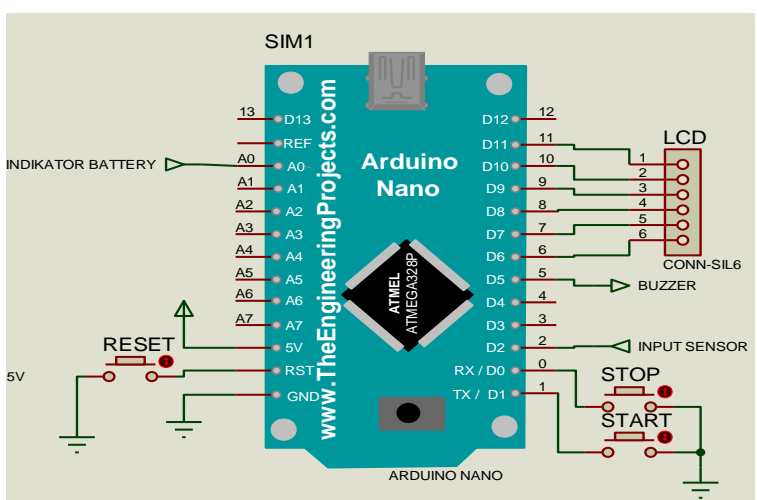

Gambar 6. Rangkaian Sistem Minimum Mikrokontroller Arduino 328

\section{Rangkaian Tombol}

Rangkaian tombol pada gambar dibawah ini merupakan masukan dari mikrokontroler. Rangkaian ini sebagai tombol 'start' atau 'stop'. Rangkaian tombol terhubung pada kaki 1 (D1) di mikrokontroler sebagai tombol start, kaki 2 (D0) sebagai stop (Abdul Kadir, 2013).

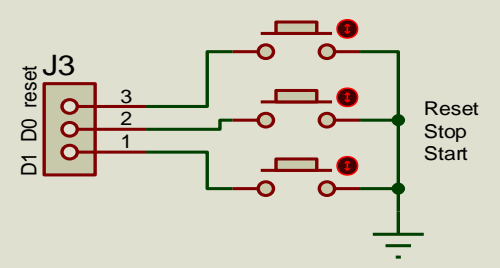

\section{Gambar 7. Rangkaian Tombol}

\section{Rangkaian Pendeteksi Sensor}

Dalam pembuatan alat penghitung tetesan pada alat infus dibutuhkan sensor dimana sensor ini digunakan untuk mendeteksi tetesan yang masuk ke drip chamber. Rangkaian ini berfungsi untuk mendeteksi jika terdapat tetesan yang masuk pada drip chamber dan mendeteksi tetesan ketika telah habis atau tidak menetes. Pada rangkaian ini penulis menggunakan optocoupler (foto dioda) dan dilengkapi beberapa komponen diantaranya, operational-amplifier, diode, dan beberapa buah resistor.

Optocoupler terdiri dari Infrared dan fotodioda yang dipisahkan oleh jarak. Jarak itulah yang digunakan sebagai tempat untuk menghitung setiap tetesan dan pendeteksian dari cairan infus apakah menetes atau tidak. Apabila pada selang infus mengalami perubahan keadaan, maka pada sensor akan mengalami perubahan tegangan (Radius Dwiatmojo. 2010).

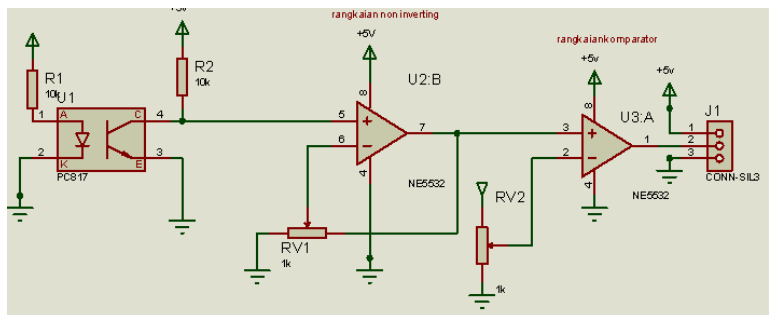

Gambar 8. Rangkaian Pendeteksi Sensor

Perubahan tegangan pada keluaran optocoupler tersebut selanjutnya akan masuk kedalam rangkaian komparator dan akan dibandingkan dengan referensi yang telah diset atau diatur sebelumnya. Diperlukan rangkaian komparator pada rangkaian ini adalah karena output dari rangkaian komparator adalah sinyal digital, hal ini sesuai dengan mikrokontroler yang menggunakan sinyal digital. Selain itu juga hanya terdapat dua kemungkinan pada rangkaian sensor yaitu pada saat media gelap karena adanya cairan infus. Fotodioda tidak mendapat bias sehingga membuat output komparator menjadi +Vsat. Pada saat media terang, fotodioda mendapat bias dan bekerja, sehingga output komparator berubah menjadi -Vsat. Selanjutnya keluaran dari rangkaian sensor ini akan menjadi masukan di mikrokontroler pada port dan port.

Ada beberapa hal yang harus diperhatikan dalam pembuatan rangkaian sensor ini, yaitu :

a. Usahakan Infra Red (iRed) dan fotodioda berhadapan secara langsung/lurus dan tidak berubah-ubah posisinya, sehingga intensitas cahaya yang diterima oleh fotodioda nantinya bisa konstan.

b. Arus yang melewati infra red dibuat stabil sehingga intensitas cahaya yang dihasilkan konstan.

\section{Rangkaian Pengisi Baterai}

Rangkaian ini memberikan tegangan untuk baterai sebesar $+4,8 \mathrm{Vdc}$. Lalu tegangan tersebut didistribusikan ke rangkaian mikrokontroler dan rangkaian display LCD (Albert Paul, Malvino. 2003)

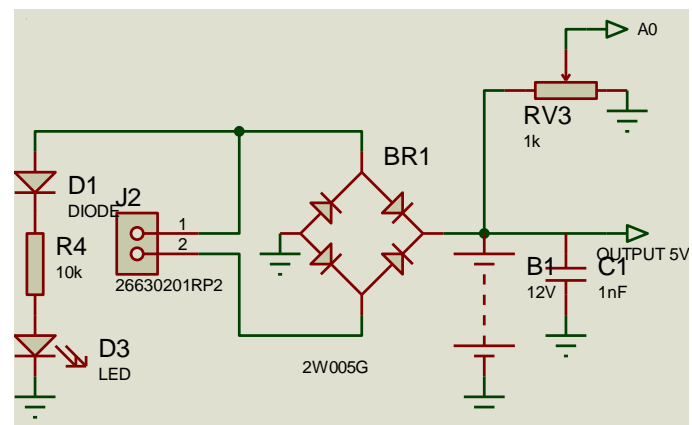

Gambar 9. Rangkaian Pengisi Baterai 


\section{Perencanaan Perangkat Lunak}

Perangkat lunak (software) yang dibuat menggunakan bahasa $\mathrm{C}$ dalam program arduino yang dipakai untuk memberikan intruksiinstruksi pada IC mikrokontroler Atmega 328. Program utama dari perancangan perangkat lunak dapat dilihat dalam diagram alur atau flow chart yang menyajikan prosedur untuk menjalankan program sesuai dengan yang diharapkan. Pada bagian ini akan diatur mulai dari pendefinisian input dan output (inisialisasi port) hingga proses pengolahan data berjalan sesuai dengan rancangan.

Untuk mengaktifkan alat monitoring jumlah tetesan cairan pada infus konvensional ini, hubungkan alat ke sumber tegangan baterai. Kemudian tekan switch pada posisi on, maka akan terjadi proses inisialisasi. Tekan tombol 'start' untuk memulai pembacaan input-an sensor, lalu timer akan bekerja seiringan dengan pembacaan inputan sensor begitu juga dengan volume cairan yang telah digunakan. Setelah waktu berjalan selama 1 menit, hasil jumlah tetesan dan volume cairan yang telah digunakan akan ditampilkan di display. Setiap satu menit berikutnya alat akan otomatis menampilkan jumlah tetesan dan volume cairan lalu menambahkan dari menit sebelumnya (Abdul Kadir, 2013).

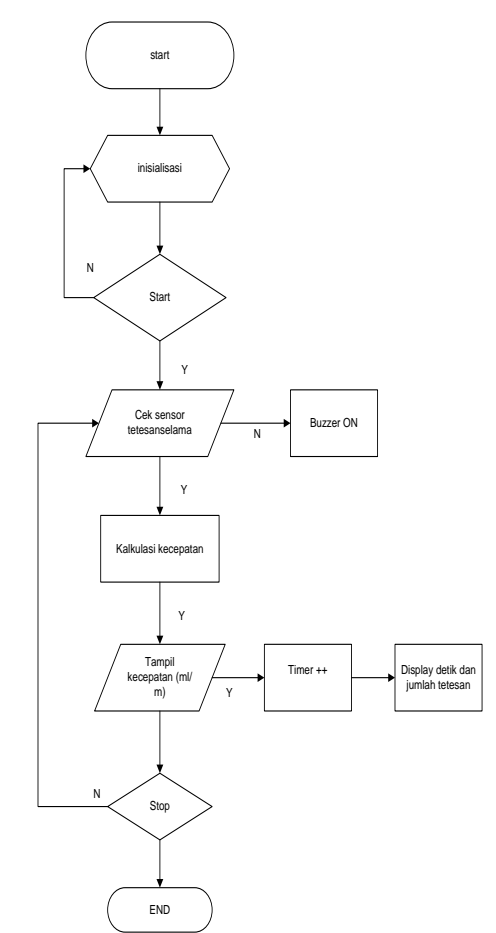

Gambar 9. Flowchart Perangkat Lunak

\section{DUDUKAN PENDETEKSIAN TETESAN}

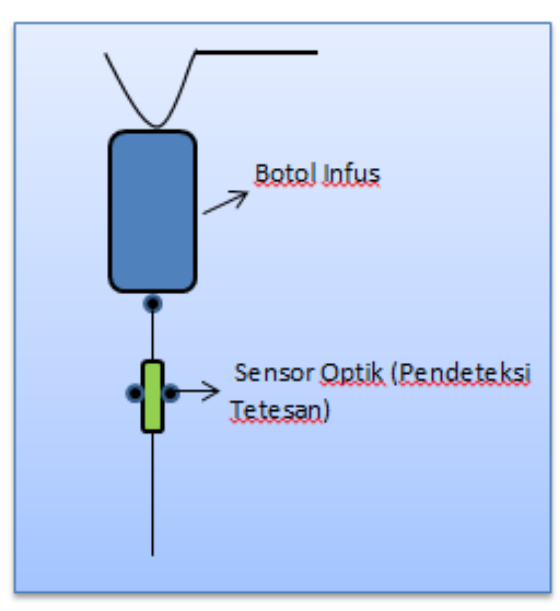

Gambar 10. Sensor Tetesan

Dikarenakan alat ini mendeteksi tetesan yang terdapat pada chamber/tabung tetesan maka dudukan posisi pancaran cahaya infra merah harus tepat mengenai ke arah turunnya tetesan yaitu tepat ditengah tabung tetesan. Sehingga LED Infra merah, tetesan dan foto dioda dirancang sedemikian rupa sehingga terdapat pada satu garis lurus. Maka dari itu dirancang sebuah dudukan tabung tetesan dan selang infus agar sensor cahaya dapat tepat mendeteksi objek yang dideteksi yaitu tetesan. Untuk lebih jelasnya dapat dilihat pada Gambar 10.

\section{SIMPULAN}

Setelah melakukan proses pembuatan modul, melakukan pendataan dan menganalisa data hasil dari pengujian, maka penulis dapat mengambil kesimpulan sebagai berikut:

1. Agar tetesan dapat dideteksi oleh sensor infra merah maka pemancar, penerima, dan chamber harus ditempatkan dalam satu garis lurus

2. Bahwa alat dapat bekerja dengan baik sesuai dengan perencanaan dengan tingkat akurasi yang cukup baik yaitu $96.2 \%$, dengan tingkat kesalahan yaitu $3.8 \%$.

3. Sistem pendeteksi yang dirancang juga bekerja sesuai dengan perencanaan yaitu aktif saat adanya kesalahan yaitu botol kosong atau tetesan tidak menetes ke drip chamber.

4. Suara yang dihasilkan buzzer masih terdengar jelas dengan nilai tingkat kebisingan cukup tinggi dan tidak berbahaya bagi pendengaran perawat berdasarkan nilai ambang tingkat kebisingan meskipun keadaan di ruangan perawat dalam kondisi ramai. 



\section{DAFTAR PUSTAKA}

Abdul Kadir. 2013. Panduan Praktis: Mempelajari Aplikasi Mikrokontroler dan Pemrogramannnya Menggunakan Arduino. Penerbit Andi

Albert Paul, Malvino. 2003. Prinsip-Prinsip Elektronika. Edisi Tiga. Jakarta: Salemba Teknika.

Dian Wiris. 2012. http://dianwiris.blogspot. com/2012/12/infus-dan-transfusidarah. $\mathrm{html}$ ? $\mathrm{m}=1$.

Galih ND. 2014. Makalah Infus. https://galihnd.wordpress.com/2014/03/12/ makalah-infus/
Jazi Eko Istiyanto. 2014. Pengantar Elektronika \& Instrumentasi Pendekatan Project Arduino \& Android. Penerbit Andi.

Ninie Purnamasari.

2011. http://ninniepurnamasari.wordpress.com/2 011/12/29/rumus-rumus-hitungan dalam keperawatan/

Radius Dwiatmojo. 2010. Meningkatkan Kinerja Infrared Optocoupler dengan Teknik Modulasi Cahaya. Jurnal Kolaborasi Elektrikal. Universitas Negeri Jakarta.
Wikipedia 2016.
Drip
Chamber. https://en.wikipedia.org/wiki/drip_chamber 